\title{
THE AGE OF DESIGN - HOW USERS PERCEIVE THE CHRONOLOGICAL ORDER WITHIN AUTOMOBILE GENERATIONS
}

\author{
Kiessling, Jonathan Max; \\ Kern, Franziska; \\ Reichelt, Florian; \\ Holder, Daniel; \\ Maier, Thomas \\ Institute for Engineering Design and Industrial Design, University of Stuttgart
}

\begin{abstract}
The vehicle exterior design conveys a variety of visual information. Among these are the brand identity, assumed characteristics, and the vehicle's age or newness. While previous research focusses mainly on the first two attributes, we broaden the perspective by examining the age perception for vehicle model portfolios across brands.

Information of age is embedded not only in branding but also in the entirety of a vehicle's exterior design features. Therefore, this paper examines how participants of a self-reported study perceive individual models inside successive product portfolios without typical branding. The stimulus patterns were derived from 12 different series of BMW, Mercedes-Benz and Audi and edited accordingly. A total of 67 models from the years 1968 to 2019 were presented and evaluated in terms of perceived age, model and brand recognition.

The results show that most vehicles are perceived as newer than their actual age, successive model generations are clearly distinguishable and participants were able to sort all models in their correct chronological order. Finally, design-related age perception and knowledge-based age perception are introduced as possible underlying concepts of the visual perception of product age.
\end{abstract}

Keywords: Product perception, Design generations, Product families, Industrial design, Platform strategies

\section{Contact:}

Kiessling, Jonathan Max

University of Stuttgart

IKTD

Germany

jonathan.kiessling@iktd.uni-stuttgart.de

Cite this article: Kiessling, J. M., Kern, F., Reichelt, F., Holder, D., Maier, T. (2021) 'The Age of Design - How Users Perceive the Chronological Order within Automobile Generations', in Proceedings of the International Conference on Engineering Design (ICED21), Gothenburg, Sweden, 16-20 August 2021. DOI:10.1017/pds.2021.559 


\section{INTRODUCTION}

This paper deals with the question of how we estimate the age of vehicles. It is not about the aging of an individual vehicle during usage, but rather about the perceived age of the vehicle design and styling. The investigation builds on the basic scheme of product perception and a self-reported study.

\subsection{Basic scheme of product perception}

In order to describe the perception in more detail, the basic scheme for product design is used (Figure 1). The product consists of the essential components layout, shape, colour and surfaces as well as graphics (Seeger, 2014; Holder et al., 2018). The layout describes the basic structure and assembly. The shape builds on the layout and defines the external appearance of the product. This includes the lines and transitions of the surfaces. The colour or surface determines product properties such as colour tones, shading and textures. Fonts and symbols are part of the graphics.

All four components contribute to the overall impression of the product. The viewer perceives the product and assesses it based on the information received, which leads to a course of action. The scheme is completed by external influences and embedded in an environment. This can, for example, be about the context of the presentation or the situation in which the viewer encounters the product.

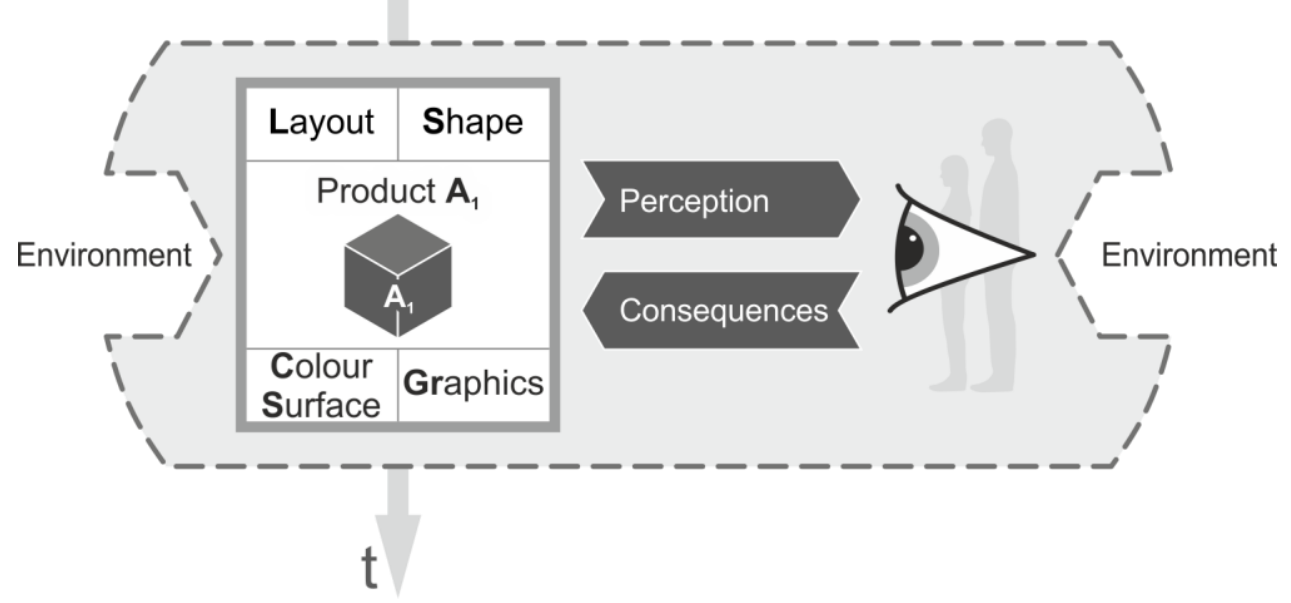

Figure 1. Basic scheme of product perception

With the basic scheme, the Figure 2 could be described as follows. The layout corresponds to a 2-box structure or an AC (Additive-Cubic) structure (cf. Holder, 2016). The shape is generally vaulted, but there are indentations in the lower area of the front and side surfaces. The colour of the car is white metallic with the distinctive colours black and silver in the radiator grille and the side mirrors. Graphic elements can be found in the form of the brand logo on the radiator grille. The vehicle is presented in daylight in a neutral setting. The perspective of the viewer corresponds to that of a pedestrian.

The breakdown into individual sub-forms enables a differentiated consideration of the vehicle perception as well as the influencing factors and their depth of impact.

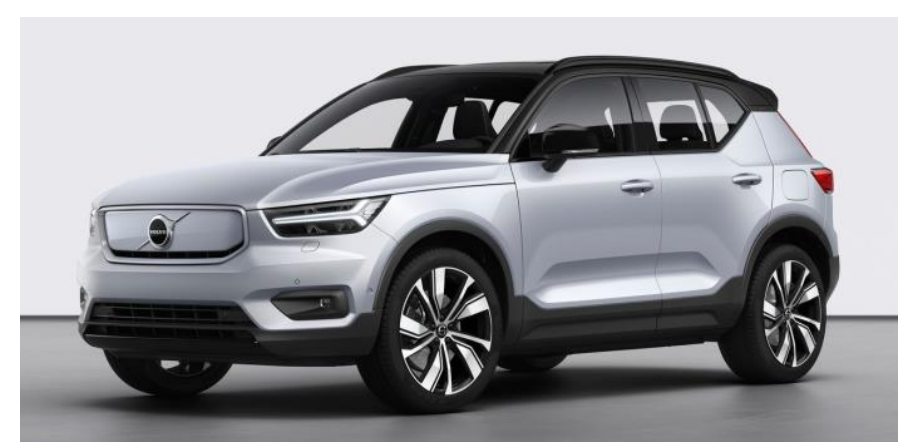

Figure 2. Application example of the basic scheme of product perception (Netcarshow 2020) 


\subsection{Age perception in product design}

The age perception of a product is determined by two factors. The first factor is design aging. For a single product, the usage is crucial. The effects can be seen in the change in colour and surface texture. In addition, invasive changes in layout and shape may result from physical impact. Proper use, care and regular maintenance can slow down the aging of the product.

The second factor is the design age of the product. This includes all partial components of product design and is determined by the product developers, engineers and designers who designed the product in line with the spirit of the times or trend. In industrial series production, this integrated design age is then reproduced until the termination of production.

Studies by Kern and Maier (2020) have shown that users are able to recognize this age implemented in the design. This results in its own set of problems. It may be that a brand new product is not perceived as such because the design age is already out of date for several years. The long development process in the automotive industry makes it even worse as the design freeze is way before the market entry. In this paper, we will therefore focus on the second factor.

\subsection{Recognition and perception of vehicles}

While the recognition of vehicles has always been of major importance, first in a military context to distinguish friend and foe (Briggs and Goldberg, 1995), the perception of automobiles gained in value in recent decades. This is primarily because certain vehicle models are not just simple objects that get you from A to B, but are also, to a large extent, aesthetic and high-priced products that are intended to convey corresponding brand values.

The automotive industry is heavily relying on the insight of market researchers and psychologists in planning and decision-making. The three main areas of interest are brand recognition, perception of car characteristics due to styling and user acceptance. Table 1 shows the focus of previous research work, which is discussed below. It also shows, in brackets, topics that were not in the focus but still mentioned in the respective work.

Brand recognition is a central component of a company's corporate design, as the brand should communicate the manufacturer's values. In their work, Karjalainen and Snelders (2010) investigated the connection between product design and the strategic direction of the brand. Ranscombe et al. (2012) used automobiles as an example to examine not only brand recognition but also to what extent the character traits communicated and intended by the brand corresponded to the perceived characteristics. Hyun et al. (2017) extended their survey setting to brand recognition in a given time window and included a gaze analysis. With eye tracking implemented, they were able to identify relevant design features for brand recognition.

Other researchers approached brand recognition with objective and mathematical methods. McCormack et al. (2004) used parametric images of design features with shape grammar rules to synthesize the design language of individual brands. Catalano et al. (2007) also applied an information technology methodology. Li et al. (2018) concentrated on the vehicle fronts with their area-oriented approach. With the help of machine learning, they developed a cluster of vehicle brands and their representatives in the form of individual models.

Similar methodological approaches can be found in the perception of car characteristics. Based on a data mining approach to search, prepare and calculate similarities in image material, Kato and Tsuda (2016) related design features with perceived vehicle properties. Ostrosi et al. (2019) also used machine image processing to develop characteristic lines in order to visualize culture and origin-dependent car styles.

However, there are also classic studies with test subjects to research perceived car properties. Regarding this topic Chen et al. (2007) and Holder et al. (2018) conducted research. The former investigated the influence on the perception of specific car characteristics with the help of various combinations of design features on automobiles. The findings were collected using a semantic differential. Holder et al. (2018), on the other hand, focused their work on the radiator grille and identified design features and their implied properties.

Another study by Holder (2016) dealt with the third component, user acceptance. In order to determine the users' satisfaction rating, different vehicle variants were set up and evaluated using questionnaires and eye tracking. In the context of user acceptance, Coughlan and Mashman (1999) should be mentioned too. In this study, the test subjects were asked to repeatedly evaluate prototypes in sync with the product development process. The aim of this cumbersome methodology was to ensure a high level of customer acceptance and financial success of the product. 


\begin{tabular}{|c|c|c|c|c|c|c|c|c|c|c|c|}
\hline \multirow[b]{2}{*}{ References } & \multicolumn{7}{|c|}{ Research Methods } & \multicolumn{4}{|c|}{ Research Focus } \\
\hline & 蛋 & 总 & 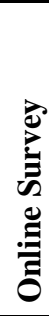 & 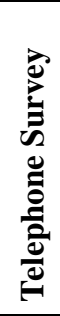 & 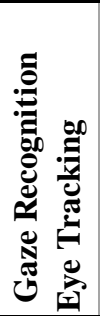 & 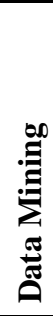 & 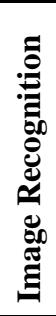 & 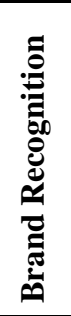 & 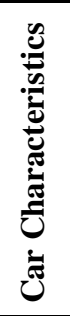 & 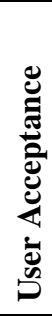 & 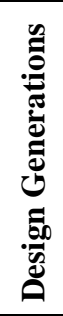 \\
\hline Briggs \& Goldberg 1995 & & $\mathrm{x}$ & & & & & & $(\mathrm{x})$ & $(\mathrm{x})$ & & \\
\hline Catalano et al. 2007 & & & & & & & $\mathrm{x}$ & $\mathrm{x}$ & & & \\
\hline Chen et al. 2007 & & $\mathrm{x}$ & & & & & & & $\mathrm{x}$ & & \\
\hline Coughlan \& Mashman 1999 & $\mathrm{x}$ & $\mathrm{x}$ & & & & & & & & $\mathrm{x}$ & $(\mathrm{x})$ \\
\hline Holder 2016 & & $\mathrm{x}$ & & & $\mathrm{x}$ & & & & $\mathrm{x}$ & $\mathrm{x}$ & \\
\hline Holder et al. 2018 & & $\mathrm{x}$ & & & & & & & $\mathrm{x}$ & & \\
\hline Hyun et al. 2017 & & $\mathrm{x}$ & & & $\mathrm{x}$ & & $\mathrm{x}$ & $\mathrm{x}$ & $\mathrm{x}$ & & \\
\hline Kajalainen \& Snelders 2010 & $\mathrm{x}$ & $\mathrm{x}$ & & & & & & $\mathrm{x}$ & $\mathrm{x}$ & & $\mathrm{x}$ \\
\hline Kato \& Tsuda 2016 & & & & & & $\mathrm{x}$ & $\mathrm{x}$ & & $\mathrm{x}$ & & \\
\hline Li et al. 2018 & & & & & & & $\mathrm{x}$ & & $\mathrm{x}$ & & \\
\hline McCormack et al. 2004 & & & & & & & & $\mathrm{x}$ & $\mathrm{x}$ & & $\mathrm{x}$ \\
\hline Ostrosi et al. 2019 & $\mathrm{x}$ & & & & & & & & $\mathrm{x}$ & & \\
\hline Ranscombe et al. 2012 & & & $\mathrm{x}$ & & & & & $\mathrm{x}$ & & & \\
\hline
\end{tabular}

Some of the presented studies include a historical point of view in the form of design generations. They take the development of the brand into consideration but miss the influence of time itself on design and styling. We therefore want to broaden the research realm by linking existing scientific approaches to the concept of age perception. Previous research shows a clear gap when it comes to comparing the exterior design of consecutive generations of the same product in combination with model and brand recognition. If product generations are included at all, they are usually only a projection screen for the specific brand development over time.

With this study we want to verify, that every product has a brand-independent design age that speaks for itself. For this purpose, research is conducted, whether users are able to sort products in their correct chronological order even without visible brand features. Therefore, both generational and cross-brand stimuli are implemented in the experimental setup for the first time. Thus, the following methodology was developed to examine said field.

\section{METHODOLOGY}

For the purpose of evaluating the perception of product generations based on the exterior styling an online survey was created. As stimulus patterns, vehicles of Central European brands were used to ensure a high degree of recognisability, since a high participation of Central Europeans in the study was assumed. Vehicle models by the brands Audi, BMW and Mercedes were selected. Furthermore, these selected brands are known for a rather consistent design development: Regarding the design development of different models, changes of the brand-specific design language between generations and across the model portfolio can be characterized as evolutionary and therefore as consistent design strategies.

The decision on the respective models was based on the considerations to obtain a long period of (historical) existence and comparable layout design (cf. Figure 1). As for the temporal restrictions, models were chosen with at least more than three generations, which resulted in a maximal covered 
timespan of 51 years for the models Audi 100 (later A6). Regarding the vehicle layout models were chosen, which can be categorized in one of the following vehicle classifications by EU regulation No. 1400/2002 (European Commission, 2002): C, D, E or F. This led to a total amount of 67 car generations divided between 12 series of 3 brands (Table 2).

Table 2. Overview of examined vehicles

\begin{tabular}{|c|c|c|c|c|}
\hline \multirow[t]{2}{*}{ Brand } & \multicolumn{4}{|c|}{ Vehicle category (EU Regulation) } \\
\hline & C: Medium cars & D: Large Cars & E: Executive cars & F: Luxury cars \\
\hline \multirow[t]{10}{*}{ Audi } & A3 & $80 / \mathrm{A} 4$ & $100 / \mathrm{A} 6$ & $\mathrm{~V} 8 / \mathrm{A} 8$ \\
\hline & 1996 & 1972 & 1968 & 1988 \\
\hline & 2003 & 1978 & 1976 & 1994 \\
\hline & 2012 & 1986 & 1982 & 2002 \\
\hline & & 1991 & 1990 & 2009 \\
\hline & & 1994 & 1997 & 2017 \\
\hline & & 2000 & 2004 & \\
\hline & & 2004 & 2011 & \\
\hline & & 2007 & 2018 & \\
\hline & & 2015 & & \\
\hline \multirow[t]{8}{*}{$\mathrm{BMW}$} & 1 Series & 3 Series & 5 Series & 7 Series \\
\hline & 2004 & 1975 & 1972 & 1977 \\
\hline & 2011 & 1982 & 1981 & 1986 \\
\hline & 2019 & 1990 & 1987 & 1994 \\
\hline & & 1998 & 1995 & 2001 \\
\hline & & 2005 & 2003 & 2008 \\
\hline & & 2011 & 2010 & 2015 \\
\hline & & 2019 & 2017 & \\
\hline \multirow{7}{*}{$\begin{array}{l}\text { Mercedes- } \\
\text { Benz }\end{array}$} & A-Class & C-Class & E-Class & S-Class \\
\hline & 1997 & 1993 & 1985 & 1972 \\
\hline & 2004 & 2000 & 1995 & 1979 \\
\hline & 2012 & 2007 & 2002 & 1991 \\
\hline & 2018 & 2014 & 2009 & 1998 \\
\hline & & & 2016 & 2005 \\
\hline & & & & 2013 \\
\hline
\end{tabular}

\subsection{Stimulus pattern creation}

For comparative observation and perception, a uniform presentation of the chosen models is absolutely necessary. For this purpose, each vehicle model was displayed from two viewing angles sideways from the front and rear. This enables a cognitive creation of a 3D model by the viewers (Shepard and Metzler, 1971). For the presentation, photos and realistic renderings of the respective models were selected and homogenized. The colour scheme was chosen and prepared (silver car colour with coloured indicators and lights), all recognizable brand and type markings were removed and a uniform grey to white gradient background was added. Thus, an influence or conditioning of the vehicle perception due to disturbance variables in the image could be avoided. Figure 3 shows an example of a stimulus pattern created in this way and used in the study. 


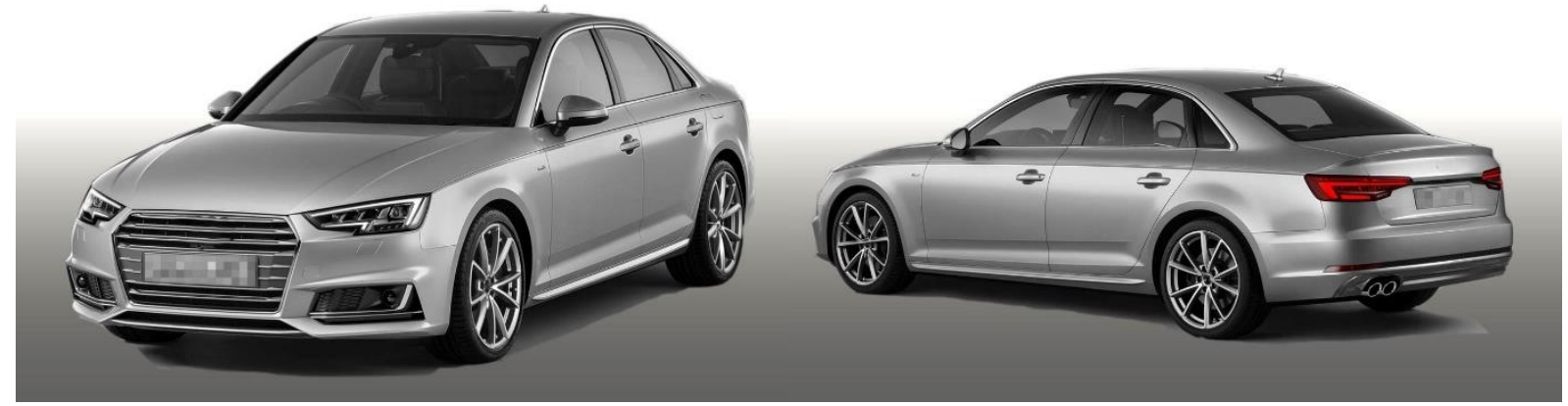

Figure 3. Stimulus pattern example, consisting of two views of the same vehicle

\subsection{Survey}

The study design was a self-reported online survey using the tool EvaSys by the University of Stuttgart; it took place from January to February 2020. Participants were recruited via personal invitation, social media as well as professional networks. A total of 85 participants generated 72 complete data sets. The sample consisted of $76,4 \%$ men and $22,2 \%$ women within an age range of 17 to 63 years, with a 70 load of participants in the age between 20 and 35 years. The participants evaluated one stimulus pattern at a time in terms of age, brand and model one by one in a randomized succession. They stated the estimated release year as an open answer and selected a specific brand out of five brands and, within that brand, one model out of five models using radio buttons. Opt-out choices were provided as "specific brand without a specific model" as well as "None of the above". Based on this collected data conclusions about the age perception, the recognition of brand and model could be derived. Subsequently, a statistical analysis with both descriptive and inferential methods was conducted. Using the statistics software IBM SPSS, the data was processed with the following methods:

- $\quad$ Shapiro-Wilk-Test: analysis for normal distribution (Kuhlenkasper \& Handl, 2019)

- $\quad$ Spearman rank-correlation test (Siebertz et al., 2017)

- Multiple linear regression analysis (Schwarz, 2020)

\section{RESULTS}

The self-reported online survey gained results regarding the perceived age of products based on their exterior design as well as interdependent factors influencing said perceived age. Additionally, brand perception and model recognition possibly influence how participants perceive the age of different vehicles. Focussing on the perceived age, the main results and influencing factors are described below.

\subsection{Main findings}

In general, the perceived age is not normally distributed for a majority of the covered vehicles, based on Shapiro-Wilk tests. Therefore, the following results were found using adequate methods. The accuracy of age assessment is defined by the deviation of the perceived age from the actual age for each examined vehicle. It does not change based on the progress of the survey. Concerning the age perception of the vehicle generations there are two main findings resulting from the survey.

First, examined products are generally assessed as newer than their actual age, as shown for the examined vehicles in Table 3. The mean deviation shows the accuracy of age perception. A deviation greater than zero means a vehicle was perceived as newer than its actual age, negative deviation vice versa. The variance shows the precision in the participants' assessment of the vehicles' age. This assessment varies among the three examined brands, for different vehicle models, and for different model generations. For example, the Audi A3 is perceived as the "newest" of the examined vehicles, while the Mercedes-Benz C-Class is assessed accurately and precisely. The newest generations of multiple vehicles, e.g. Audi A6 (2018), BMW 1 Series (2019) or BMW 3 Series (2019), are assessed as less new than they actually are. Several factors possibly influencing this assessment across the examined portfolios are discussed after the description of the survey's main results.

Another main finding is that the participants perceived distinctive model generations for all examined vehicles, as shown in Figure 4. The actual release year is marked with black diamonds; newer age perception and accuracy are clearly shown by quartile range. Subsequent generations are assessed as newer than their predecessors for all 67 examined vehicles. The mean and median perceived age of every 
examined vehicle is newer than their predecessor and older than their successor. These generations are shown as box plots illustrating the mean assessed age as well as the distribution of the perceived age per vehicle. Even though these distributions intersect, the participants assessed the vehicles' age as distinguishable generations. This shows that the participants perceive the chronological order within the automobile generations in the correct historical order for all 67 examined models.

Table 3. Deviation of age perception cumulated per model

\begin{tabular}{|l|r|r|}
\hline Brands and models & Mean deviation of age perception [a] & Variance $\boldsymbol{\sigma}[\mathbf{a}]$ \\
\hline Audi & 2,47 & 2,23 \\
\hline Audi A3 & 4,31 & 2,97 \\
\hline Audi A4 & 2,34 & 2,19 \\
\hline Audi A6 & 1,77 & 1,89 \\
\hline Audi A8 & 1,46 & 1,85 \\
\hline BMW & 1,89 & 2,69 \\
\hline BMW 1 Series & $-0,22$ & 2,93 \\
\hline BMW 3 Series & 2,46 & 2,80 \\
\hline BMW 5 Series & 2,34 & 3,16 \\
\hline BMW 7 Series & 2,97 & 1,86 \\
\hline Mercedes-Benz & 1,58 & 1,54 \\
\hline Mercedes-Benz A-Class & 0,51 & 2,23 \\
\hline Mercedes-Benz C-Class & 0,95 & 0,60 \\
\hline Mercedes-Benz E-Class & 1,57 & 1,18 \\
\hline Mercedes-Benz S-Class & 3,28 & 2,12 \\
\hline
\end{tabular}
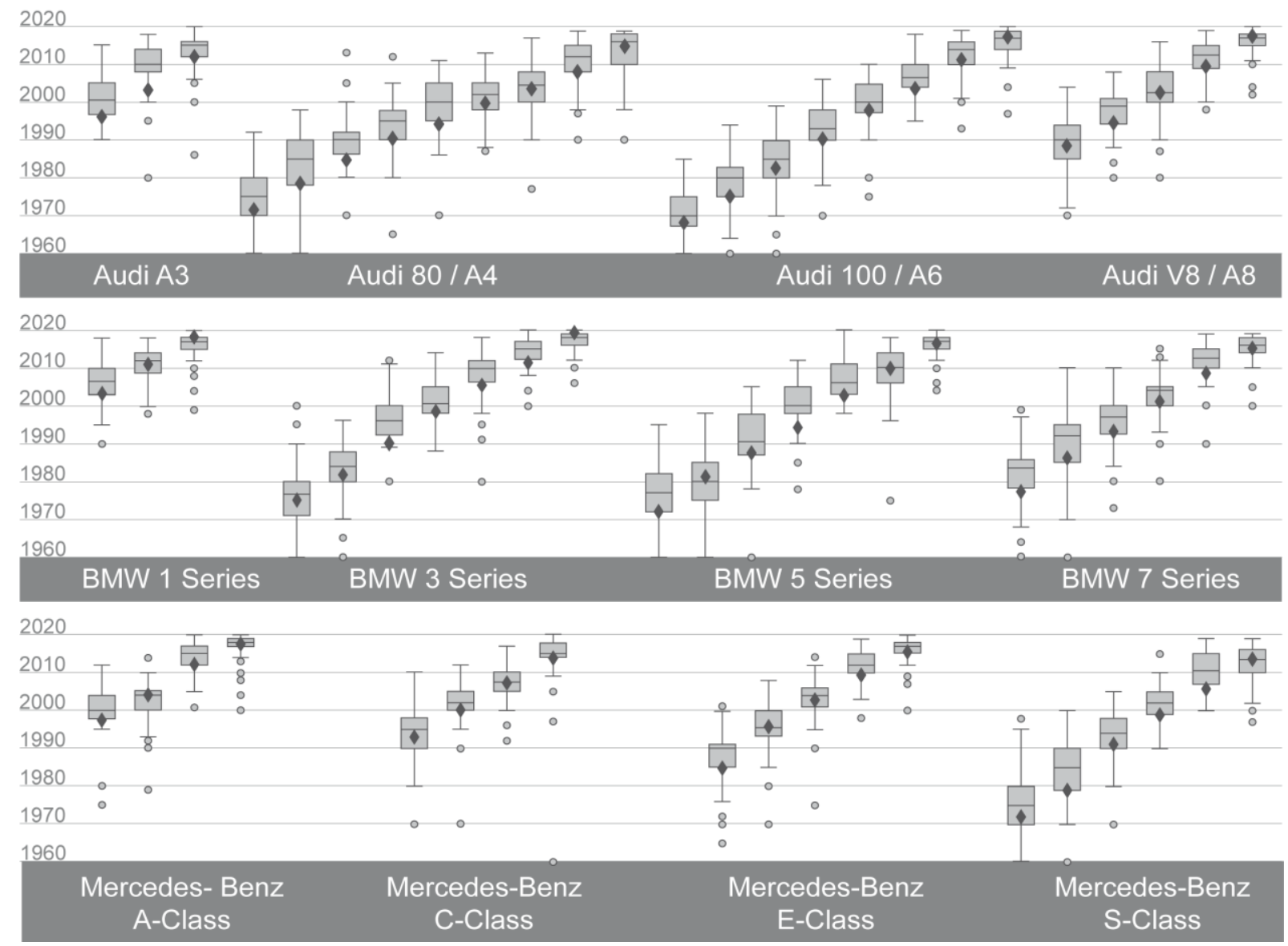

Figure 4. Perceived chronological order within automobile generations 


\subsection{Influences and exclusions}

Since recognizable branding features were removed from the stimulus patterns, the participants recognized the vehicles and their age by their exterior design features. Several factors can be excluded from influencing the perceived age of the examined vehicles while others show a significant effect or the need for further discussion.

Since older participants are in general more likely to have witnessed multiple generations of one vehicle model being released, a correlation between the participant's age and the vehicle age perception was assumed and tested. Surveying self-reported interest in product styling in general and automotive styling in particular aims at indicating the participants' knowledge and familiarity when stating the perceived age of the vehicles. The participants' age as well as their interest in industrial design and automotive design respectively have no significant influence on the age assessment accuracy (Spearman analysis).

The participants' self-reported knowledge of the three examined brands correlates positively $(r=0.721$, $p=0,001, N=72$ ) with the number of identified vehicles and correctly assessed release years. Newer vehicles' age is assessed significantly more precisely than older vehicles' age (Spearman $(r=0.570$, $\mathrm{p}=0,001, \mathrm{~N}=72$ ). Model recognition probably effects age perception since the participants' knowledge of a certain model can include knowledge about its release year. For the examined models, there was no clearly quantifiable relation between product recognition and age perception for the whole sample. Indicators for possible influences are described in the following.

To summarize the factors influencing the perceived age of vehicles, the participants' knowledge of the examined vehicles as well as the vehicles' age seem to be the most important factors. However, product recognition leaves the most room for discussion as to whether age perception depends on identifying a vehicle correctly. Therefore, the results show the need for further discussion and potential for further research.

\section{DIscussion}

The following part of the paper focusses on limitations, interesting individual cases, and possible explanations for the described results of the survey.

The choice of brands and vehicle models limits the survey's scope. The focus is on German brands and participants living in Germany. Therefore it can be assumed, that the participants are familiar with the examined vehicles. The high self-reported knowledge of the three examined brands confirms this. Furthermore, the three examined brands share common market segments and are direct competitors. The survey focusses on only a part of current and historic product portfolios, vehicle categories, brands and markets. Also the survey focussed on subsequent models. Model updates were excluded to limit the time scope of the survey and to enable a clearer differentiation of the examined models. As for the scope of the examined vehicles and the sample of participants, there is no significant dependence between the participants' age or age range and their age perception. The results of a similar survey might differ for a different international market context.

Since the sequence of stimulus patterns was randomized and the age perception accuracy did not vary depending on the progress of the survey, a learning effect or decline in the participants' perception during the survey can be assumed non-existent. The conceptual design of the survey is therefore a valid method for identifying product recognition and age perception for different vehicles. Consistently high self-reported knowledge of the examined brands and high interest in the topic indicate a well-informed sample. Therefore, a distortion effect of the analysis cannot be excluded due to previous knowledge of the participants. This is also shown in the significant correlation of brand knowledge and the number of correctly identified vehicles.

In everyday life, the participants mostly encounter specific vehicles after their market release. At the same time, designers often aim at creating new or more futuristic styles for newly released vehicles compared to previous generations. This states a possible explanation for the participants assessing most vehicle generations as newer than they actually are. In addition, since there is a newness threshold, examined vehicles cannot be assessed as newer than the release year of 2020. However, the analysis can be filtered to remove the resulting bias. When analysing all vehicles except for the ones from the last decade, there is no more significant correlation between the vehicles' actual age and their age perception accuracy.

Brand recognition for the examined sample is on such a consistently high level that this paper focusses only on the relation of age perception and model recognition. Especially, the possible correlation between model recognition and age assessment leaves room for discussion. Nearly half of the 
examined vehicles showed significant correlations therein, while the other half did not. Therefore, model recognition and the intrinsic knowledge of specific models might affect the assessment of the perceived age. On the other hand, a vehicle's exterior design can indicate the vehicle's age. Several participants perceive this external knowledge even without correctly identifying the model itself. Therefore, two different ways of age perception seem probable: design-related age perception and knowledge-based age perception. In this study, the first way is predominantly relevant, which however does not invalidate the second.

These discussed aspects show the potential of a closer examination of vehicle exterior stylings and design features affecting the perception and assessments of subsequent vehicle generations inside a consistent portfolio.

Radical paradigm shifts in vehicle exterior design are visible in the age perception of subsequent model generations. Between the second and third generation of the Mercedes-Benz A-Class the layout switched from IC (Integrative-Cubic) to AC (Additive-Cubic), based on Holder (2016). This leads to a greater difference between the perceived model generations and results in the previous model being perceived as relatively older than its actual age in retrospective. As an opposite to radical design changes and generation leaps, evolutionary design with minor exterior changes leads to a more blurred age perception, for example in the age perception of the 1994 Audi 80 and its successor, the 2000 Audi A4. For the examined product portfolios, all three brands follow a mainly evolutionary design strategy with clearly subsequent model generations. The survey participants perceive the age of these generations accordingly as a sequence.

\section{CONCLUSION AND OUTLOOK}

In conclusion, the study design enabled a distinctive measurement of age perception without influencing the participant due to brand or model specific signatures and emblems. Therefore, the participants perceived the vehicles' age in distinguishable generations. The main factors influencing said age perception are product recognition and exterior design paradigm shifts, as seen with the Mercedes-Benz A-Class. The generations differ in variance and in their mean value. Due to a newness threshold, the newer vehicles' age is perceived more exactly. However, when model generations can be clearly distinguished by their exterior design, the perceived generations are also more distinguished. Most model generations - with exception of the newness bias of current models - are mainly perceived as newer than they actually are. These factors (product recognition and product newness) seem to be the main influences on product age perception for the example of well-known, German vehicle exterior design generations.

However, further observations of the study leave room for constructive research concerning the influence of the vehicles' exterior design on age perception. In several cases, the participants recognize the age of a vehicle correctly inside a defined threshold without recognizing the vehicle model itself. An influence of the perceived vehicle exterior design on the age recognition can be assumed. Therefore, future research may focus on the influence of specific design features on the perceived age. A different scope of international automotive brands, product portfolios, and participants would probably show different results for the perceived age of vehicle exterior designs. Thus, future research needs to clarify and further investigate the direct influence of design features on the age recognition. Furthermore, the shown method may be used to evaluate design prototypes in the product development process. Although an expansion of the investigation with more models, even including international vehicles, seems to be a logical next step, the study already shows that German manufacturers follow evolutionary styling strategies with styling interdependencies among models and successive generations and thus created a perceivable design legacy.

\section{REFERENCES}

Briggs, R. W., \& Goldberg, J. H. (1995), “Battlefield recognition of armored vehicles”, Human factors, Vol. 37 No. 3, pp. 596-610. https://doi.org/10.1518/001872095779049381

Catalano, C. E., Giannini, F., Monti, M., \& Ucelli, G. (2007), "A framework for the automatic annotation of car aesthetics", Artificial Intelligence for Engineering Design, Analysis and Manufacturing: AI EDAM, Vol. 21 No. 1, pp. 73-90. https://doi.org/10.1017/S0890060407070151.

Chen, L. L., Kang, H. C., \& Hung, W. K. (2007), "Effects of design features on automobile styling perceptions", IASDR 07, The Hongkong Polytech University, 12.11.2007-15.11.2007, pp. 16. 
Coughlan, P., \& Mashman, R. (1999), "Once is not enough: repeated exposure to and aesthetic evaluation of an automobile design prototype”, Design Studies, Vol. 20 No. 6, pp. 553-563. https://doi.org/10.1016/S0142694X(99)00007-1.

European Commission (2002), Distribution and Servicing of Motor Vehicles in the European Union Explanatory Brochure of Commission Regulation (EC) No. 1400/2002 of 31 July 2002. [online] Available at: https://ec.europa.eu/competition/sectors/motor_vehicles/legislation/explanatory_brochure_en.pdf (25.11.2020).

Holder, D. (2016), Gefallensurteil und Blickanalyse zum Fahrzeugdesign zukünftiger Aufbaugestalten anhand einer technischen Prognose, Stuttgart, Universität Stuttgart.

Holder, D., Inkermann, D., Krasteva, P., Vietor, T., Maier, T. (2018), "Integrated Product Gestalt Design Method for the Analysis and Definition of Interface Elements Regarding Exterior and Interior", Proceedings of the 20th Congress of the International Ergonomics Association (IEA 2018), Cham, Switzerland, Springer, pp. 888-897. http://dx.doi.org/10.18419/opus-9045.

Hyun, K. H., Lee, J. H., \& Kim, M. (2017), "The gap between design intent and user response: identifying typical and novel car design elements among car brands for evaluating visual significance", Journal of Intelligent Manufacturing, Vol. 28 No. 7, pp. 1729-1741. https://doi.org/10.1007/s10845-015-1176-8.

Karjalainen, T. M., \& Snelders, D. (2010), "Designing visual recognition for the brand", Journal of Product Innovation Management, Vol. 27 No. 1, pp. 6-22. https://doi.org/10.1111/j.1540-5885.2009.00696.x.

Kato, T., \& Tsuda, K. (2016), "Study of sensitivity knowledge for quantitative evaluations to the car exterior design”, Procedia Computer Science, Vol. 96, pp. 1106-1111. https://doi.org/10.1016/j.procs.2016.08.152.

Kern, F. \& Maier, T. (2020), "Eine Frage der Zeit - Alterswahrnehmung in der Mensch-Produkt-Interaktion", GfA Frühjahrskongress 2020: Digitaler Wandel, digitale Arbeit, digitaler Mensch?, Berlin, 16.03.202018.03.2020, GfA-Press, Dortmund, pp. 6.

Kuhlenkasper, T., \& Handl, A. (2019), Einführung in die statistische Auswertung von Experimenten: Theorie und Praxis mit R, Springer Spektrum, Berlin. https://doi.org/10.1007/978-3-662-59054-6.

Li, B., Dong, Y., Wen, Z., Liu, M., Yang, L., \& Song, M. (2018), “A machine learning-based framework for analyzing car brand styling”, Advances in Mechanical Engineering, Vol. 10 No. 7, pp. 1-17. https://doi.org/10.1177/1687814018784429.

McCormack, J. P., Cagan, J., \& Vogel, C. M. (2004), "Speaking the Buick language: capturing, understanding, and exploring brand identity with shape grammars", Design studies, Vol. 25 No. 1, pp. 1-29. https://doi.org/10.1016/S0142-694X(03)00023-1.

Netcarshow (2020), Volvo 2020 XC40 Recharge. [online] Available at: https://www.netcarshow.com/volvo/2020-xc40_recharge/1280x960/wallpaper_0a.html (24.11.2020).

Ostrosi, E., Bluntzer, J. B., Zhang, Z., \& Stjepandić, J. (2019), "Car style-holon recognition in computer-aided design”, Journal of Computational Design and Engineering, Vol. 6 No. 4, pp. 719-738. https://doi.org/10.1016/j.jcde.2018.10.005.

Ranscombe, C., Hicks, B., Mullineux, G., \& Singh, B. (2012), "Visually decomposing vehicle images: Exploring the influence of different aesthetic features on consumer perception of brand", Design Studies, Vol. 33 No. 4, pp. 319-341. https://doi.org/10.1016/j.destud.2011.06.006.

Schwarz, J. (2020), Methodenberatung. [online] Universität Zürich,. Available at: https://www.methodenberatung.uzh.ch/de.html (02.06.2020).

Seeger, H. (2014), Basiswissen Transportation-Design: Anforderungen - Lösungen - Bewertungen, Springer Fachmedien, Wiesbaden. https://doi.org/10.1007/978-3-658-04449-7

Shepard, R. N., \& Metzler, J. (1971), "Mental rotation of three-dimensional objects”, Science, Vol. 171 No. 3972, pp. 701-703. https://doi.org/10.1126/science.171.3972.701.

Siebertz, K., van Bebber, D., Hochkirchen, T. (2017), Statistische Versuchsplanung - Design of Experiments $(D o E)$, Springer Vieweg, Berlin, Heidelberg. https://doi.org/10.1007/978-3-662-55743-3. 